\title{
Mortalidad entre los pacientes en tratamiento con metadona e infectados con el virus de la inmunodeficiencia humana $y / 0$ hepatitis $C$
}

\author{
Mortality rate in patients on methadone treatment \\ and infected with the human immunodeficiency \\ virus and/or the hepatitis C virus
}

\author{
Roberto lozano*, Nieves Domeque**, Concepción Perálvarez**, Maria-Dolores Torrellas**, \\ Cielos Gonzalo**. \\ * Servicio de Farmacia, Hospital Real de Nuestra Señora de Gracia, Zaragoza, SALUD. ** Unidad asistencial especializada en \\ tratamiento ambulatorio de los trastornos adictivos por consumo de sustancias (UASA). Hospital Real de Nuestra Señora de \\ Gracia, Zaragoza, SALUD.
}

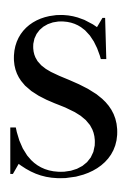

r. Director:

La adicción a la heroína es una enfermedad recidivante crónica con graves consecuencias, particularmente en términos de prematura y alta mortalidad (Hser, Hoffman, Grella y Anglin, 2001). Los programas de tratamiento de mantenimiento con metadona (TMM) han demostrado ser eficaces para reducir el uso ilícito de opioides, y el riesgo de infección por el virus de la inmunodeficiencia humana (VIH) y/o virus de la hepatitis C (VHC), entre otras variables (Kleber, 2008; Pedrero-Pérez y MethaQoL, 2017).

A pesar de todo, la tasa de mortalidad anual entre los pacientes incluidos en programas de TMM, aproximadamente del $1 \%$, es más de 10 veces superior al de la población general (Zanis y Woody, 1998); constituyendo la sobredosis y la infección por VIH y otros virus transmitidos por la sangre (p.e. VHC) las causas más comunes de muerte (Roncero, Vega, Martinez-Raga y Torrens, 2017).

En efecto, entre los drogodependientes por vía parenteral e infectados por VIH, la co-infección por VIH y VHC se observa en el $50 \%-95 \%$ de los casos (Muga, Roca, Egea, Tor, Sirera y Rey-Joly, 2000); pudiendo provocar, dicha infección simultanea por VIH, una mayor carga viral del VHC y una evolución más rápida a la cirrosis hepática y sus complicaciones (Santos y Sanz, 2004; Elizalde, Iñarrairaegui, Rodríguez y Zozaya, 2004).

Por todo ello, el objetivo del presente estudio consistió en analizar la influencia de la infección por VIH y/o VHC en la supervivencia de los pacientes incluidos programas de TMM.

Para ello, se realizó un estudio observacional retrospectivo, con un período de seguimiento de 10 años (2005-
2014), analizando la mortalidad por cualquier causa en una cohorte de pacientes heroíno-dependientes incluidos en el programa de TMM de la unidad asistencial especializada en tratamiento ambulatorio de los trastornos adictivos por consumo de sustancias (UASA) del Hospital Real de Nuestra Señora de Gracia de Zaragoza.

La muestra estuvo compuesta por 299 pacientes al inicio del período de estudio (2005) y 253 al final del mismo (2014). A partir de los registros incluidos en la historia clínica electrónica y/o manual se obtuvieron los datos correspondientes al sexo, edad, índice de masa corporal, dosis metadona, años de permanencia en el programa de TMM, diagnóstico de infección por VIH y/o VHC, y mortalidad.

Los pacientes fueron distribuidos en 4 grupos, en función de la presencia o ausencia de infección por VIH y/o VHC (no-infectados, grupo 1; infectados por VIH, grupo 2; co-infectados por VIH y VHC, grupo 3; infectados por VHC, grupo 4); calculándose tanto la mortalidad conjunta por cualquier causa (porcentaje de muertes respecto al total de pacientes al inicio, $n=299$ ) como la tasa bruta de mortalidad (TBM) para cada uno de los 4 grupos, expresada, esta última, como el número de muertes por 100 pacientes-año de seguimiento. Finalmente se evaluó la influencia de la infección por VIH y/o VHC sobre la mortalidad global, comparando los datos de TBM de los grupos 2 al 4 con el grupo 1, este último como comparador.

Como resultado, al final del período de estudio de diez años, se registraron 45 muertes $(15.4 \%)$ y unos valores de TBM de $0.9 \%, 2.2 \%, 2.6 \%$ y $1.7 \%$ para los grupos del 1 al 4 , respectivamente. Por otra parte, al analizar la influencia de

Recibido: Agosto 2017; Aceptado: Enero 2018

Enviar correspondencia a:

Roberto Lozano. Servicio de Farmacia. Hospital Real de Nuestra Señora de Gracia. Ramón y Cajal 60.5000 Zaragoza.

E-mail: rlozano@salud.aragon.es 
la infección por VIH y/o VHC sobre la TBM, unicamente al comparar dicho valor en el grupo 3, correspondiente a los pacientes co-infectados por VIH y VHC, con el obtenido en el grupo 1, correspondiente a pacientes no-infectados, se obtuvo una diferencia suficientemente amplia como para ser estadísticamente significativa (co-infectados por VIH y VHC, $2.6 \%$ vs. no-infectados, $0.9 \%$; $\mathrm{p}=.0113$ ). No obstante, al considerar conjuntamente los pacientes VIH de los grupos 2 y 3 y los pacientes VHC de los grupos 3 y 4 , también en ambos casos la diferencia en la TBM fue de mas del doble y estadísticamente significativa al compararlas con el grupo control: 28 muertos (años seg.=114) vs. 9 (años seg. $=87$, $p=.0104^{*}$ ) y 27 muertos (años seg.=122) vs. 9 (años seg. $=87$, $\left.p=.0271^{*}\right)$ para VIH y VHC, respectivamente. Tabla 1.

Los datos obtenidos parecen indicar que la infección por VIH y/o VHC, pero sobre sobre todo la co-infección, jugarían un papel fundamental en la morbi-mortalidad entre estos pacientes, sin olvidar otros factores directamente relacionados con ellas, como p.e. efectos secundarios, interacciones o toxicidad intrínseca de los fármacos empleados en su tratamiento, así como los utilizados para otras comorbilidades psiquiátricas e infecciosas, que con elevada frecuencia pueden resultar hepatotóxicos.

De esta manera, tanto la introducción de los nuevos antiretrovirales y esquemas terapéuticos, como el control de la adherencia al tratamiento (González-Álvarez, Madoz-Gúrpide, Parro-Torres, Hernández-Huerta y Ochoa Mangado, 2017) y sus efectos secundarios, en el tratamiento de los pacientes con SIDA; así como la adopción de los nuevos antivirales de acción directa para el tratamiento de la hepatitis C (Roncero et al., 2017), aún sin introducir en la práctica clínica al final del período de estudio utilizado en

Tabla 1. Caracteristicas de los pacientes y Resultados.

\begin{tabular}{|c|c|c|c|c|}
\hline Variable & $\begin{array}{c}\text { Grupo } 1 \\
\text { No-infecc. }\end{array}$ & $\begin{array}{c}\text { Grupo } 2 \\
\text { Infecc.VIH }\end{array}$ & $\begin{array}{c}\text { Grupo } 3 \\
\text { Co-infecc. } \\
\text { VIH-VHC }\end{array}$ & $\begin{array}{c}\text { Grupo } 4 \\
\text { Infecc. VHC }\end{array}$ \\
\hline \multicolumn{5}{|c|}{ Características de los pacientes } \\
\hline Edad, años & $47(7.7)$ & $48(7.5)$ & $47(8)$ & $46(6.6)$ \\
\hline Mujeres, No. (\%) & $26(28)$ & $20(43)$ & $16(19)$ & $22(32)$ \\
\hline $\mathrm{IMC}, \mathrm{kg} / \mathrm{m}^{2}$ & $25.6(3.4)$ & $24(4)$ & $23(4)$ & $26(6)$ \\
\hline Años en TMM & $15(7.7)$ & $16(7.6)$ & $15.3(8)$ & $13.8(6.6)$ \\
\hline Dosis MTD, mg & $56(32)$ & $61(41)$ & $65(35)$ & $55(31)$ \\
\hline \multicolumn{5}{|l|}{ Resultados } \\
\hline Pacientes, №. (\%) & $92(30.8)$ & $54(18.1)$ & $85(28.4)$ & $68(22.7)$ \\
\hline Exitus, No. (\%) & $9(9.8)$ & $10(18.5)$ & $18(21.2)$ & $9(13.2)$ \\
\hline Años-paciente & 87 & 45 & 69 & 53 \\
\hline TBM (\%) & 0.9 & 2.2 & 2.6 & 1.7 \\
\hline Test de Fisher $(p)$ & comparador & .0734 & $.0113^{\star}$ & .092 \\
\hline
\end{tabular}

Nota. Todos los datos se expresan como media $( \pm D S)$, a menos que se indique lo contrario. * $p \leq .05 ; \mathrm{DS}=$ desviación estandar; IMC = índice masa corporal; MTD = metadona; No.= número; $\mathrm{TBM}=$ tasa bruta mortalidad; $\mathrm{TMM}=$ tratamiento de mantenimiento con metadona. este trabajo (2014), son considerados factores clave para el aumento de la supervivencia en este tipo de pacientes.

Finalmente, debe anotarse, como limitaciones más importantes del estudio, el no haber podido valorar, a causa de la pequeña muestra y/o dificultad de obtención datos, la influencia de otros factores como p.e. sexo, edad, otras substancias adictivas o tratamientos farmacológicos para la comorbilidad infecciosa y/o psiquiátrica.

\section{Conflicto de intereses}

Los autores declaran no tener ningún conflicto de interés.

\section{Referencias}

Elizalde, I., Iñarrairaegui, M., Rodríguez, C. y Zozaya, J. M. (2004). Treatment of chronic hepatitis C virus infection. Anales del Sistema Sanitario de Navarra, 27, 81-90.

González-Álvarez, S., Madoz-Gúrpide, A., Parro-Torres, C., Hernández-Huerta, D. y Ochoa Mangado, E. (2019). Relationship between alcohol consumption, whether linked to other substance use or not, and antiretroviral treatment adherence in HIV+ patients. Adicciones, 31, 8-17. doi:10.20882/adicciones.916.

Hser, Y. I., Hoffman, V., Grella, C. E. y Anglin, M. D. (2001). A 33-year follow-up of narcotics addicts. Archives of General Psychiatry, 58, 503-508. doi:10.1001/archpsyc.58.5.503.

Kleber, H. D. (2008). Methadone maintenance 4 decades later: Thousands of lives saved but still controversial. Journal of the American Medical Association, 300, 23032305. doi:10.1001/jama.2008.648.

Muga, R., Roca, J., Egea, J. M., Tor, J., Sirera, G. y Rey-Joly, C. (2000). Mortality of HIV-positive and HIV-negative heroin abusers as a function of duration of injecting drug use. The Journal of Acquired Immune Deficiency Syndromes, 23, 332-338.

Pedrero-Pérez, E. J. y MethaQoL, G. (2017). Methadone dosage and its relationship to quality of life, satisfaction, psychopathology, cognitive performance and additional consumption of non-prescribed drugs. Adicciones, 29, 3754.doi:10.20882/adicciones.831.

Roncero, C., Vega, P., Martinez-Raga, J. y Torrens, M. (2017). Chronic Hepatitis C and people with a history of injecting drugs in Spain: population assessment, challenges for effective treatment. Adicciones, 29, 71-73. doi:10.20882/adicciones.908.

Santos, I. y Sanz, J. (2004). Tratamiento con interferón y ribavirina de la hepatitis crónica por virus $\mathrm{C}$ en pacientes con infección por VIH. Anales de Medicina Interna, 21, 369-372.

Zanis, D.A. y Woody, G. E. (1998). One year mortality rates following methadone treatment discharge. Drug and Alcohol Dependence, 52, 257-260. doi:10.1016/S03768716(98)00097-0. 